Overall, this study is an excellent example of how 4D flow CMR can be used to gain quantitative insights into the pathophysiology of single-ventricle circulation. As 4D flow techniques become incorporated into clinical CMR studies, serial assessment of ventricular flow patterns may provide a noninvasive method of detecting subclinical disease.

\section{References}

1. Sato T, Calderon RJ, Klas B, Pedrizzetti G, Banerjee A. Simultaneous volumetric and functional assessment of the right ventricle in hypoplastic left heart syndrome after Fontan palliation, utilizing 3-dimensional speckle-tracking echocardiography. Circ J. 2020;84:235-44.

2. Michel M, Logoteta J, Entenmann A, Hansen JH, Voges I, Kramer HH, et al. Decline of systolic and diastolic 2D strain rate during follow-up of HLHS patients after Fontan palliation. Pediatr Cardiol. 2016;37:1250-7.
3. Campbell MJ, Quartermain MD, Cohen MS, Faerber J, Okunowo O, Wang Y, et al Longitudinal changes in echocardiographic measures of ventricular function after Fontan operation. Echocardiography. 2020;37:1443-8.

4. Kaneko S, Khoo NS, Smallhorn JF, Tham EB. Single right ventricles have impaired systolic and diastolic function compared to those of left ventricular morphology. J Am Soc Echocardiogr. 2012;25:1222-30.

5. Eriksson J, Dyverfeldt P, Engvall J, Bolger AF, Ebbers T, Carlhäll CJ. Quantification of presystolic blood flow organization and energetics in the human left ventricle. Am J Physiol Heart Circ Physiol. 2011;300:H2135-41.

6. Stoll VM, Loudon M, Eriksson J, Bissell MM, Dyverfeldt P, Ebbers T, et al. Testretest variability of left ventricular 4D flow cardiovascular magnetic resonance measurements in healthy subjects. J Cardiovasc Magn Reson. 2018;20:15.

7. Eriksson J, Bolger AF, Ebbers T, Carlhäll CJ. Four-dimensional blood flowspecific markers of LV dysfunction in dilated cardiomyopathy. Eur Heart J Cardiovasc Imaging. 2013;14:417-24.

8. Stoll VM, Hess AT, Rodgers CT, Bissell MM, Dyverfeldt P, Ebbers T, et al. Lef ventricular flow analysis. Circ Cardiovasc Imaging. 2019;12:e008130.

9. Stone ML, Schafer M, Dimaria MV, von Alvensleben JC, Campbell DN Jaggers J, et al. Diastolic inflow is associated with inefficient ventricular flow dynamics in Fontan patients. J Thorac Cardiovasc Surg. 2022;163:1195-207.

\title{
Commentary: Time to climb the ladder of causation
}

\section{William M. DeCampli, MD, PhD}

In a book published in 2018, Turing Awardee Judea Pearl and Dana MacKenzie wrote of the need for science to climb the "ladder of causation," moving above association, passing through intervention, and finally arriving at counterfactuals, where one can finally address causation. ${ }^{1}$ Stone and colleagues $^{2}$ used cardiac magnetic resonance imaging to calculate previously described 4 components of end diastolic blood volume in 10 patients with hypoplastic left heart syndrome, hypoplastic right heart syndrome, and controls. ${ }^{2}$ Compared with controls, patients with hypoplastic left heart syndrome and hypoplastic right heart syndrome had less direct flow volume (DF) and more residual volume (as a percentage of end diastolic volume [EDV]). Based on

\footnotetext{
From the College of Medicine, University of Central Florida, and The Heart Center, Arnold Palmer Hospital for Children, Orlando, Fla.

Disclosures: The author reported no conflicts of interest.

The Journal policy requires editors and reviewers to disclose conflicts of interest and to decline handling or reviewing manuscripts for which they may have a conflict of interest. The editors and reviewers of this article have no conflicts of interest.

Received for publication July 28, 2021; revisions received July 28, 2021; accepted for publication July 28, 2021; available ahead of print Aug 3, 2021.

Address for reprints: William M. DeCampli, MD, PhD, The Heart Center, Arnold Palmer Hospital for Children, 83 W Miller St, Orlando, FL 32813 (E-mail: William.decampli@orlandohealth.com).

J Thorac Cardiovasc Surg 2022;163:1209-10

0022-5223/\$36.00

Copyright (C) 2021 by The American Association for Thoracic Surgery

https://doi.org/10.1016/j.jtcvs.2021.07.046
}

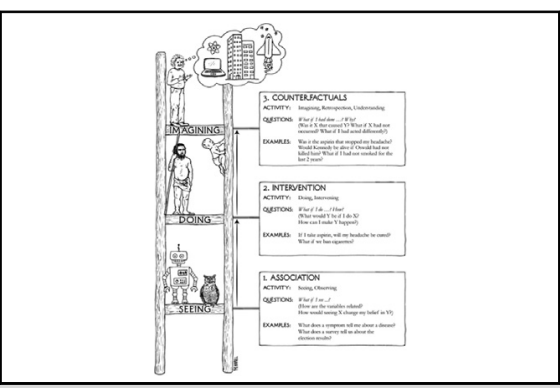

Associations lie at the bottom of the Ladder of Causation. Let's climb the ladder!' (c) 2018. Reprinted by permission of Basic Books, an imprint of Hachette Book Group, Inc.

CENTRAL MESSAGE

The association of CMR-derived components of diastolic volume with conventional measures of ventricular function is intriguing, if not mysterious. Science must determine the causal relationships.

these measurements, the authors concluded that these patients have "inefficient flow patterns" and diastolic dysfunction.

The use of these diastolic component volumes as indicators of diastolic function and originated in a 2011 article that hypothesized that diastolic flow patterns could 
"preferentially optimize a portion of EDV for effective and rapid systolic ejection by virtue of location near and motion towards the LV outflow tract." ${ }^{3}$ This hypothesis has never been proven and can be challenged by at least a couple of facts. First, the energy imparted to inflow by diastolic relaxation is about one-thousandth the energy imparted to blood during systole. It is hard to imagine that this tiny amount of energy has any influence on the systolic ejection of blood. Second, the hypothesis ascribes the "intelligent" arrangement of flow entirely to diastolic function, whereas the final compartment volumes are significantly (and perhaps dominantly) determined by the contractile pattern of the next systole. As a result, investigators have posited secondary hypotheses attempting to assert the beneficial effects of diastolic flow pattern, such as its ability to prime the aortic valve for ejection, act as a buffer to redistribute kinetic energy to reduce transfer of it to potential energy that would result in elevated ventricular pressure, and prevent blood stasis and thrombus formation. ${ }^{2,4}$ None of these hypotheses have been proven.

In the quest to understand the meaning of these component flow patterns, perhaps one should consider reversing cause and effect. There is ample evidence for associations among the component volumes (particularly DF and DF kinetic energy) and conventional measures of function such as ejection fraction, EDV, end systolic volume, circumferential strain, and even the 6-minute walk test. $^{2,3,5}$ These associations suggest that structural, metabolic, and mechanical derangements of the myocardium affecting the conventional measures may also be the cause of abnormal diastolic flow patterns. After all, flow patterns in the ventricular chamber are entirely generated by the anatomy and mechanics of the ventricle and its coupling to the atrium and aorta. Based on the energy argument already mentioned, it would appear less likely that the abnormal diastolic flow patterns, in turn, cause further ventricular dysfunction.
What really happens must be determined by some good science-a combination of physiological measurements and numerical mechanical modeling of the functioning myocardium and chamber blood flow. These models exist. ${ }^{6,7}$ One could show, for example, how certain patterns of myocardial relaxation and contraction alter the component volumes, and that these myocardial patterns also influence ejection fraction, circumferential strain, and EDV. One could also determine whether or not diastolic flow patterns have any appreciable causal effect on ventricular function.

Despite these challenges, there is no doubt that these component volume measurements correlate with some conventional measures of ventricular function, and they may be more sensitive and reliable measures of function. For this reason, there is value in what Stone and colleagues ${ }^{2}$ accomplished by measuring these quantities for the first time in single-ventricle congenital heart disease. One hopes that their work also motivates physiologists to uncover why component volume measurements are indicative of function, thus reaching the top of the Ladder of Causation.

\section{References}

1. Pearl J, MacKenzie D. The Book of Why: The New Science of Cause and Effect. New York, NY: Hachette Book Group, Inc; 2018.

2. Stone ML, Schäfer M, DiMaria MV, von Alvensleben JC, Campbell DN, Jaggers J, et al. Diastolic inflow is associated with inefficient ventricular flow dynamics in Fontan patients. J Thorac Cardiovasc Surg. 2022;163:1195-207.

3. Eriksson J, Dyverfeldt P, Engvall J, Bolger AF, Ebbers T, Carlhall CJ. Quantification of presystolic blood flow organization and energetics in the human left ventricle. Am J Physiol Heart Circ Physiol. 2011;300:H2135-41.

4. Rodriguez F, Green GR, Dagum P, Nistal JF, Harrington KB, Daughters GT, et al. Left ventricular volume shifts and aortic root expansion during isovolumic contraction. J Heart Valve Dis. 2006;15:465-73.

5. Stoll VM, Hess AT, Rodgers CT, Bissell MM, Dyverfeldt P, Ebbers T, et al. Left ventricular flow analysis: novel imaging biomarkers and predictors of exercise capacity in heart failure. Circ Cardiovasc Imaging. 2019;12:e008130.

6. Li JKJ, Kaya M, Kerkhof PLM. Quantitative cardiology and computer modeling analysis of heart failure in systole and in diastole. Comp Biol Med. 2018;103:252-61.

7. Chung CS, Shmuylovich L, Kovacs SJ. What global diastolic function is, what it is not, and how to measure it. Am J Physiol Heart Circ Physiol. 2015;309:H1392-406. 